\title{
A SUBFUNÇÃO INTERACIONAL DE “CHECAGEM” NA GRAMÁTICA TEXTUAL-INTERATIVA
}

\author{
Eduardo Penhavel ${ }^{1}$ \\ Alessandra Regina Guerra ${ }^{2}$
}

\section{RESUMO}

Na Gramática Textual-interativa, os Marcadores Discursivos são definidos mediante a combinação de traços linguísticos referentes a um conjunto de parâmetros de análise. Um desses parâmetros diz respeito à função que as expressões linguísticas exercem em termos de orientação da interação. Neste trabalho, discutimos um aspecto da função de orientação da interação, procurando contribuir para tornar cada vez mais precisa a definição de Marcadores Discursivos da Gramática Textual-interativa. Especificamente, discutimos a subfunção de Checagem, aqui entendida como uma das possíveis formas de particularização da função mais geral de orientação da interação. A esse respeito, dentre outras questões que abordamos, destacamos a natureza retórica como aspecto central das expressões de Checagem e analisamos a relação entre a subfunção de Checagem e o estatuto de Marcador Discursivo, procurando demonstrar que praticamente todas as expressões com essa subfunção constituem também, necessariamente, Marcadores Discursivos.

PALAVRAS- CHAVE: marcadores discursivos; partículas discursivas; gramática textual-interativa.

\begin{abstract}
In textual-interactive grammar, discourse markers are defined through a combination of linguistic features linked to a set of parameters. One of these parameters concerns the function that linguistic expressions play in the orientation of verbal interaction. This paper discusses an aspect of this function with the purpose of contributing to specify the definition of discourse markers within textual-interactive grammar. Particularly, the paper focuses on the notion of checking, a subfunction in relation to the

1. Docente de Linguística da Universidade Federal de Viçosa (UFV).

2. Mestre em Estudos lingüísticos pela Universidade Estadual Paulista (UNESP) e docente da Universidade Federal do Mato Grosso do Sul (UFMS).
\end{abstract}


larger function of the orientation of interaction. To this respect, among other issues, the rhetoric nature of checking expressions is addressed. In addition, the relation between the subfunction of checking and the status of discourse marker is analyzed, in order to demonstrate that (almost) all the checking expressions are also, necessarily, discourse markers.

KEYWORDS: discourse markers; discourse particles; textual-interactive grammar.

\section{Considerações iniciais}

Dentre as diversas abordagens de Marcadores Discursivos (MDs daqui em diante) existentes, a abordagem da Gramática Textual-interativa destaca-se como uma das poucas que chegam a apresentar uma definição exaustivamente abrangente de MDs, no sentido de uma definição que procura delimitar todas as expressões linguísticas pertencentes a essa classe. Trata-se de uma abordagem que dispõe de um mecanismo bastante sofisticado para identificar se uma expressão funciona ou não como MD em determinado contexto e, inclusive, para identificar graus de prototipicidade de MDs.

$\mathrm{Na}$ Gramática Textual-interativa, os MDs são definidos mediante a combinação de traços linguísticos referentes a um conjunto de parâmetros de análise. Um desses parâmetros diz respeito à função que as expressões linguísticas desempenham em termos de orientação do processo de interação verbal. Trata-se do parâmetro denominado de "orientação da interação".

Considerando que esse parâmetro constitui um dos parâmetros centrais definidores de MDs e tendo em vista que alguns pontos relativos a ele ainda carecem de um tratamento mais esclarecedor e aprofundado, discutimos, neste trabalho, uma questão particular desse parâmetro, procurando especificar em que ele consiste e procurando, assim, contribuir para tornar cada vez mais clara e precisa a própria definição de MDs da Gramática Textual-interativa. Mais especificamente, o objetivo do trabalho é discutir alguns dos principais aspectos da subfunção de "Checagem", aqui assumida como uma das possíveis subfunções da função geral de "orientação da interação".

Na próxima seção, apresentamos mais detalhadamente a definição de MDs da Gramática Textual-interativa, bem como o parâmetro referente à função de orientação da interação. Na seção seguinte, discutimos, então, a subfunção de Checagem. Finalmente, numa última seção, apresentamos as considerações finais.

\section{MDs na Gramática Textual-interativa e a função de orientação da interação}

Penhavel (2010) observa que, no atual cenário dos estudos linguísticos, podem ser distinguidos três tipos gerais de abordagens de MDs com base na natureza das expressões linguísticas analisadas como tal. O primeiro tipo compreende abordagens que tomam como MDs expressões integradas a um enuncia- 
do matriz, que têm função de conexão e que se referem a um aspecto desse enunciado. Aí se incluem, por exemplo, trabalhos como o de Fraser (2006). O exemplo em (1) abaixo (FRASER, 2006, p. 190) ilustra um item considerado como MD por uma abordagem desse tipo.

(1) Donna left late. However, she arrived on time.

[Donna saiu tarde. Porém chegou a tempo.]

A segunda modalidade de abordagem compreende aquelas que analisam como MDs expressões constituindo um enunciado independente, com função de gerenciamento da conversação e que se referem a planos de referência. Um representante típico dessa modalidade é o trabalho de Fischer (2006). O item destacado no exemplo em (2) (FISCHER, 2006, p. 434) representa um MD para uma abordagem dessa modalidade.

(2) okay Danny, now that this meeting's over, we need to schedule another one so we continue, to get our work done on this project, (...)

[okay Danny, agora que essa reunião terminou, nós precisamos agendar outra e assim continuamos, para terminar nosso trabalho nesse projeto (...)]

Finalmente, o terceiro tipo de abordagem abarca aquelas que consideram como MDs expressões dos dois tipos anteriores. Essa modalidade inclui, por exemplo, a abordagem de Schiffrin (1987) e a da Gramática Textual-interativa.

A Gramática Textual-interativa (JUBRAN \& KOCH, 2006; JUBRAN, 2007), uma vertente da Linguística Textual, constitui um quadro teórico-metodológico que assume o texto como objeto de estudo, focalizando, em particular, os chamados "processos de construção textual".

Trata-se, essencialmente, dos processos de Organização Tópica, Referenciação, Parentetização, Parafraseamento, Correção e Repetição. Nesse contexto, os MDs são definidos como uma classe formada por certas expressões linguísticas que atuam na articulação e no gerenciamento dos processos de construção textual, sendo distinguidos dois tipos principais de MDs, os basicamente sequenciadores e os basicamente interacionais (razão pela qual essa abordagem pode ser incluída no terceiro tipo de abordagem de MDs acima distinguido).

Especificamente, Risso, Silva \& Urbano (2006) definem os MDs como uma classe gradiente, sendo esses elementos caracterizados, como mencionado acima, mediante a combinação de traços referentes a uma série de parâmetros de análise, ou variáveis: ${ }^{3}$

3. Assim como Guerra (2007), não consideramos, na definição de MDs, a variável "Apresentação formal”, que inclui os traços "forma única" e "forma variante", por entendermos que esses traços não são relevantes em termos definicionais. 
(i) Variável: articulação de segmentos do discurso:

Traços: sequenciador tópico; sequenciador frasal; não-sequenciador;

(ii) Variável: orientação da interação:

Traços: basicamente orientador; secundariamente orientador; fragilmente orientador;

(iii) Variável: relação sintática com a estrutura oracional:

Traços: sintaticamente independente; sintaticamente dependente;

(iv) Variável: relação com o conteúdo proposicional:

Traços: exterior ao conteúdo; não-exterior ao conteúdo; não se aplica;

(v) Variável: autonomia comunicativa:

Traços: comunicativamente autônomo; comunicativamente não-autônomo;

(vi) Variável: demarcação prosódica:

Traços: com pauta demarcativa; sem pauta demarcativa;

(vii) Variável: padrão de recorrência:

Traços: baixa frequência; média frequência; alta frequência;

(viii) Variável: transparência semântica:

Traços: totalmente transparente; parcialmente transparente; opaco; não se aplica;

(ix) Variável: massa fônica:

Traços: até três sílabas tônicas; além de três sílabas tônicas.

Com base nessas variáveis e nesses traços, MDs prototípicos são definidos como expressões que manifestam a combinação de traços apresentada em (3) abaixo, enquanto MDs não-prototípicos são definidos como expressões que manifestam essa combinação com algum desvio, o qual, de modo geral, não ultrapassa dois traços. 
(3) - sequenciador tópico e secundariamente ou fragilmente orientador; ou não sequenciador e basicamente orientador;

- sintaticamente independente;

- exterior ao conteúdo;

- comunicativamente não-autônomo;

- com pauta demarcativa;

- alta frequência;

- parcialmente transparente;

- até três sílabas tônicas.

O presente trabalho circunscreve-se à análise da variável "orientação da interação". Risso, Silva \& Urbano (2006) consideram a "orientação da interação" como uma função, desempenhada por qualquer expressão linguística em maior ou menor grau de intensidade. Assim, uma expressão pode ter a função de ser basicamente, secundariamente ou fragilmente orientadora da interação (o que corresponde, respectivamente, aos três traços da variável em foco: "basicamente orientador", "secundariamente orientador", "fragilmente orientador"). Este trabalho delimita-se, em particular, à função "basicamente orientador [da interação]”."

A função "basicamente orientador" pode ser definida como a tarefa de troca de atos discursivos ligados ao estabelecimento do comprometimento dos interlocutores com o ato de interação verbal. Risso, Silva \& Urbano (2006, p. 408) dizem o seguinte a respeito dessa função:

Uma unidade é basicamente orientadora [...], quando há uma nítida orientação por parte do falante em direção ao ouvinte, ou deste ao falante, através, por exemplo, da busca de uma aprovação discursiva (como em certo? entende?) ou da manifestação de um acompanhamento atencioso da fala do outro (uhn uhn). Nesse traço [...] se incluem também unidades que, embora possam corresponder a automonitoramentos, sinalizam formalmente um envolvimento interpessoal (como digamos).

4. A título de esclarecimento sobre a relação entre "traço" e "função", convém explicar que uma noção, por exemplo, como "basicamente orientador" (em outros termos, "orientação básica da interação") constitui uma função de uma expressão linguística. Quando se fala do traço "basicamente orientador", quer-se dizer que um traço (isto é, um aspecto, uma característica) de uma expressão é ter a função de basicamente orientador. Assim, pode-se dizer, por exemplo, que uma expressão manifesta traços como: ser sintaticamente independente, ser exterior ao conteúdo proposicional, ter a função de orientação básica da interação etc. 
Urbano (2006, p. 500-501) distingue cinco subfunções da função "basicamente orientador":

a) fático de natureza imperativa e entonação exclamativa. São formas produzidas pelo falante corrente, mas orientadas diretamente para o ouvinte: Olha!, Veja!;

b) fático de natureza ou entonação interrogativa, produzido após enunciado declarativo. São formas produzidas pelo falante após uma declaração também produzida por ele, como né?, certo?;

c) fático de natureza e entonação interrogativa, produzido após enunciado interrogativo. São formas produzidas pelo falante após uma pergunta (retórica ou não) também produzida por ele, como hein?;

d) feedbacks: São formas como uhn uhn, certo, produzidas pelo ouvinte e usadas normalmente em duas situações: 1) isoladamente, retroalimentando o falante e mantendo-o no seu papel discursivo; 2) no início do turno do ouvinte, possibilitando a este assumir o papel de falante;

e) início de respostas formas ou de comentários. [...] São formas produzidas pelo interlocutor, ao tomar o turno, em respostas, ou como comentário a perguntas ou a comentário do falante anterior, como um $A h$, de natureza exclamativa.

Na caracterização da função "basicamente orientador" de Risso, Silva \& Urbano (2006), dada acima, são apontadas por esses autores (pelo menos) três subfunções: busca de uma aprovação discursiva pelo falante; manifestação de um acompanhamento atencioso da fala do outro; sinalização formal de um envolvimento interpessoal. A primeira corresponde exatamente à função definida por Urbano (2006) em (b) acima; a segunda equivale à função em (d); a terceira, por sua vez, parece não ser prevista nas subfunções distinguidas por Urbano.

Diferindo ligeiramente da proposta de Urbano (2006) e acrescentando uma nova subfunção não prevista por esse autor nem por Risso, Silva \& Urbano (2006), entendemos que podem ser distinguidas cinco subfunções da função "basicamente orientador": 
(i) Checagem (recobre as subfunções (b) e (c) de Urbano (2006), bem como a subfunção de busca de aprovação discursiva de Risso, Silva \& Urbano, (2006));

(ii) Retroalimentação (equivalente à subfunção prevista por Urbano em (d), assim como à subfunção de acompanhamento da fala do outro, de Risso, Silva \& Urbano);

(iii) Injunção (correspondente à subfunção distinguida por Urbano em (a));

(iv) Iniciação (equivalente à subfunção proposta por Urbano em (e));

(v) Interpelação (tipo de subfunção não previsto nos outros autores). ${ }^{5}$

Neste trabalho, delimitamos nossa análise à subfunção de Checagem, adiando a discussão das outras quatro subfunções para trabalho posterior e limitando-nos a propor que elas, juntamente com a Checagem, constituem o quadro das possíveis subfunções nas quais pode particularizar-se a função mais geral "basicamente orientador".

\section{A subfunção de Checagem}

Como uma especificação da função "basicamente orientador [da interação]", a subfunção de Checagem verifica-se quando o falante "pergunta" ao ouvinte se este está entendendo determinado segmento do discurso antecedente, porém pressupondo esse entendimento, de modo que ele (falante) fique autorizado diante do ouvinte a dar prosseguimento ao discurso. O aspecto central caracterizador da subfunção de Checagem é que se trata de uma pergunta retórica, no sentido de que prevê não ser respondida pelo ouvinte e de que não se refere ao conteúdo do texto, mas à relação de interação. A máxima reação do ouvinte condizente com o ato de Checagem seria a produção de um ato de Retroalimentação.

Nos exemplos em (4) e (5) abaixo, as expressões destacadas exercem a subfunção de Checagem.

5. De acordo com a tipologia sugerida aqui, a subfunção apontada por Risso, Silva \& Urbano (2006) de sinalização formal de um envolvimento interpessoal (referente a expressões como digamos) poderia ser abarcada pela subfunção de Injunção. Porém uma análise que nos parece mais pertinente é a de que a sinalização formal de um envolvimento interpessoal não deveria ser considerada como uma função basicamente orientadora, mas como secundariamente orientadora da interação. 
(4) Doc.: e como que cê conheceu ela?

Inf.: ah num:: barzinho numa boate né? nos conhecemo(s) com o tempo peguei o telefone dela a gente::... começamo(s) a entrá(r) em contato de um tempo... pra lá a gente começô(u) a saí(r) freqüentemente... (IBORUNA: AC029; NE: L.14-17).

(5) Inf.: nós nos conhecemos na igre::ja ((risos)) num/ numa reunião de igreja que a gente ia tal... conhecemos começamo(s) a namorá(r) namorá(r)... e sabe? foi ficando aquele negócio for::te aquela coisa... for::te forte forte e eu muito obs/ obcecada por ele nossa eu era mui::to sabe?... muito obcecada por ele MESmo... e ele aquela pessoa::... ele é muito... ${ }^{6}[\text { farren::to sabe? }]^{6}[$ Doc.: ((risos))] ele gosta muito de saí::(r) e tal (IBORUNA: AC-022; NE: L.7-12). ${ }^{6}$

Em (4), é bastante evidente a natureza retórica do item "né?". Em primeiro lugar, o Informante enuncia o item e não cede o turno para uma resposta do Documentador. Além disso, pelo contexto, é possível perceber que 0 item não se refere ao conteúdo do texto. A expressão "né?" escopa o segmento "num:: barzinho numa boate", produzido pelo Informante como resposta a uma pergunta do Documentador sobre como o Informante teria conhecido uma terceira pessoa. Como se trata de uma informação requerida pelo Documentador e fornecida pelo Informante, parece muito pouco provável que este estivesse usando o item "né?" (aqui entendido como redução de "não é verdade?") para perguntar àquele sobre a veracidade da informação fornecida, porque aquele participante não teria esse conhecimento; ao contrário, tal informação seria justamente o que ele (Documentador) estaria solicitando. A nosso ver, o Informante usa a expressão "né?" para "perguntar" (pressupondo posicionamento afirmativo e ausência de resposta) se o Documentador entenderia (ou poderia imaginar) a situação de alguém conhecer outra pessoa em um bar/boate, de modo que ele (Informante) possa dar prosseguimento a seu discurso.

Similarmente, em (5), o Informante usa a expressão "sabe?" sem ceder, em seguida, o turno ao interlocutor (no caso, o Documentador), o qual, por sua vez, também não manifesta tentativa de tomada de turno, demonstrando ter interpretado a expressão do Informante não como uma pergunta a ser respondida. Na sua terceira ocorrência, por exemplo, a função de "sabe?" não seria perguntar ao Documentador se este sabe que o indivíduo descrito pelo Informante é "farrento", mas seria "perguntar" se o Documentador entende o que seria um indivíduo "farrento", de modo que ele (Informante) possa prosseguir seu discurso, com a garantia de que seu 
interlocutor o esteja acompanhando. Ou seja, não se trata de pergunta sobre conteúdo, mas sobre a dinâmica da interação verbal.

Algumas das expressões linguísticas que assumem a subfunção de Checagem aparecem listadas em (6).

(6) ahn?, hem?, uhm?, certo?, entende?, entendeu?, não?, não é?, não é verdade?, né?, ok?, sabe?, tá?, tá certo?, tá claro?, viu?.

Urbano (2006, p. 505) utiliza a noção de "busca de aprovação discursiva" para referir-se ao que tratamos aqui como sendo a subfunção de Checagem. A esse respeito, cabe aqui uma observação de caráter principalmente terminológico, mas também conceitual, em certo sentido. Um termo como "busca" pode dar a impressão de que o falante faz a pergunta de Checagem e deixa sob decisão do ouvinte conceder ou não a aprovação discursiva, isto é, a pergunta do falante seria apenas uma tentativa de alcançar a aprovação do ouvinte. No entanto, a expressão de Checagem não dá essa opção de escolha ao ouvinte. Como afirmado acima, o falante "pergunta" ao ouvinte se este está acompanhando o discurso, porém pressupõe que a resposta seja afirmativa e continua o discurso sem dar margem para a manifestação do ouvinte a esse respeito. Dessa forma, o papel do ato de Checagem seria, mais exatamente, a imposição de aprovação discursiva, e não propriamente a solicitação ou busca dessa aprovação junto ao ouvinte. Ao usar a expressão de Checagem, o falante não estaria negociando com o ouvinte a possibilidade ou não de continuar o discurso, mas estaria impondo ao ouvinte a aceitação de prosseguimento da interação.

Nesse sentido, o próprio termo "Checagem" aqui usado, na verdade, também não seria o mais adequado para rotular a subfunção em pauta, justamente porque essa subfunção não implica simplesmente checar se o ouvinte está acompanhado o discurso, mas instaurar a condição de aprovação discursiva, necessária para o prosseguimento da interação. Talvez o mais adequado fosse a utilização de rótulos como "Instauração" ou "Instanciação" de aprovação discursiva. De qualquer forma, por ora ainda adotamos a terminologia "Checagem", para manter uniformidade com outros trabalhos em que adotamos esse termo e também pela praticidade da expressão, mas tendo em vista a consideração terminológica/conceitual em foco.

Como mostrado na seção anterior, uma das subfunções basicamente orientadoras da interação distinguidas por Urbano (2006) é a subfunção de "fático de natureza e entonação interrogativa, produzido após enunciado interrogativo", podendo este enunciado interrogativo ser de natureza retórica ou não. No entanto, entendemos que não caberia distinguir uma subfunção como essa. Nossa visão é 
que esse tipo de fático, quando produzido após enunciado interrogativo retórico, tem papel exatamente equivalente ao que tratamos aqui como sendo a subfunção de Checagem.

Já no caso do fático de natureza e entonação interrogativa produzido após enunciado interrogativo não-retórico, vemos duas possibilidades de análise. Uma primeira impressão é a de que, na verdade, quanto a esse tipo de "fático", não seria pertinente falar em função de orientação da interação, pois uma expressão desse tipo estaria incidindo sobre o conteúdo do texto (solicitando, de fato, uma resposta do ouvinte), e não sobre a dinâmica interacional. O item “unh?” em (7) abaixo (URBANO, 2006, p. 505-506) permite visualizar o vínculo que esse tipo de expressão teria com a dimensão informacional do texto.

(7) Doc. - vamos dizer ... de que se compõe a universidade ... administrativamente ela se estrutura como $u h n$ ?

Inf. - aí você me apertou porque ...

A expressão “unh?", parece-nos, poderia ser interpretada como um pedido para que o interlocutor responda, de fato, o que acaba de ser perguntado, tanto que, na sequência, o Informante realmente fornece uma resposta, em termos de conteúdo, ao Documentador.

Outra hipótese de análise (talvez até mais promissora) é a de que esse tipo de fático teria a subfunção de Interpelação (proposta acima), isto é, o papel de chamar a atenção do ouvinte para a interação e alcançar seu comprometimento com ela. Nesse caso, esse tipo de fático teria, de fato, uma subfunção de orientação básica da interação, particularmente uma subfunção similar à de expressões como "Hei", "Ô" etc. (expressões que, gramaticalmente, teriam o estatuto de Vocativo).

Neste trabalho, não desenvolvemos mais detalhadamente o problema dos fáticos de natureza e entonação interrogativa produzidos após enunciados interrogativos não-retóricos, limitando-nos à proposição dessas duas hipóteses de análises e destacando que se trata de um tema bastante relevante para ser pesquisado em maior profundidade.

Outro fato que merece atenção aqui é o de que toda expressão de Checagem apresenta uma construção formalmente idêntica que atua como enunciado interrogativo propriamente, com função não-retórica. Por exemplo, "entendeu?" pode constituir um enunciado interrogativo formado apenas pelo verbo "entender" flexionado na terceira pessoa do singular do pretérito perfeito do indicativo, sendo usado, de fato, para questionar o ouvinte sobre seu entendimento do conteúdo precedente; "tá certo?" pode ser uma pergunta sobre a correção de uma informação anterior; a forma "né?" pode focalizar realmente a veracidade do conteúdo anterior, o que pode ser visto no exemplo (hipotético) abaixo (MARTELOTTA \& ALCÂNTARA, 1996, p. 278). 
(8) Mamãe vai sair hoje, né? Responda logo, porque, se ela for, eu quero ir com ela.

Como observam Martelotta \& Alcântara (1996) o item “né?", em (8), manifesta o sentido de pergunta não-retórica, que, de fato, pede ao ouvinte a confirmação do que foi dito anteriormente, o que seria evidenciado pelo fato de o falante, na sequência, dizer "responda logo, porque, se ela for, eu quero ir com ela".

A esse respeito, o que se pode observar é que as expressões de Checagem e suas construções correspondentes não-retóricas constituem formas linguísticas superficialmente idênticas com estruturas morfossintáticas (internas ou profundas) diferentes. No caso de enunciados propriamente interrogativos, trata-se de construções resultantes dos processos comuns de formação de atos interrogativos e sujeitas às possibilidades de modificação normais desses atos. No exemplo hipotético em (9) abaixo, todas as construções destacadas poderiam atuar como enunciados propriamente interrogativos, como formas de questionar a correção da informação precedente.

(9) O Brasil é um país rico, tá certo? / tá certo isso? / estaria certo isso? / tá totalmente certo isso?

Já as expressões de Checagem são expressões cristalizadas, que não são resultantes de uma construção morfossintática do falante e não estão sujeitas a qualquer tipo de modificação. São expressões já prontas que os falantes selecionam diretamente do léxico da língua. Em (9), apenas a forma "tá certo?" seria passível de interpretação como ato de Checagem. A forma "viu?", por exemplo, atua como ato de Checagem, mas o mesmo não poderia ocorrer com construções como "via?", "vimos?", "tu viste?", "viu bem?" etc.

Dessa forma, em termos gramaticais, entendemos que as expressões de Checagem são sempre interjeições, no sentido de serem expressões necessariamente cristalizadas (e considerando também outras razões não relevantes aqui especificamente). Essa parece a análise mais pertinente, tendo em vista que a implementação de qualquer tipo de arranjo morfossintático na estrutura interna dessas expressões ou o acréscimo de qualquer tipo de modificador sobre elas seriam procedimentos que afetariam seu estatuto de pergunta retórica e, portanto, seu estatuto de ato "meramente" de Checagem.

Nesse sentido, quando se analisa, por exemplo, um ato de Checagem como "certo?", consideramos que o adequado não seria dizer que se tem aí um adjetivo, ou uma oração formada apenas por um adjetivo, assumindo a subfunção interacional de Checagem. O que se vê aí seria uma interjeição com essa subfunção. Provavelmente, a expressão “certo?” seja, de fato, resultante de um sintagma adjetival 
ou de alguma estrutura oracional, por meio de algum processo de mudança linguística, mas, enquanto ato de Checagem já fixado na língua, parece que o mais plausível seria tratá-la, gramaticalmente, como uma interjeição. E o mesmo seria válido para todas as demais expressões de Checagem, inclusive aquelas constituídas por mais de um elemento, como “tá certo?", “tá claro?”, "não é?” etc.

Convém salientar aqui que, apesar de os atos de Checagem e suas construções não-retóricas correspondentes serem resultantes de processos de construção gramatical diferentes, suas formas superficiais, como mencionado, parecem ser totalmente idênticas. Assim, o reconhecimento, pelo ouvinte, de uma forma como sendo um ato de Checagem ou um enunciado interrogativo não-retórico é um processo que depende exclusivamente de fatores contextuais. Por essa razão, o uso de expressões de Checagem ou de construções correspondentes não-retóricas podem gerar situações de ambiguidade, sobretudo quando tais expressões e construções escopam outros enunciados completos, e não apenas partes de enunciados. Naturalmente, tais situações de ambiguidade podem ser resolvidas pelo contexto ou por esclarecimentos explícitos entre os interlocutores, porém as próprias expressões/construções interrogativas, em si, não fornecem nenhuma pista sobre seu estatuto de Checagem ou de enunciado propriamente interrogativo.

Por fim, uma constatação que nos parece consideravelmente esclarecedora quanto à subfunção de Checagem diz respeito à relação entre essa subfunção e o estatuto de MD. Observe-se que, aqui, estamos discutindo apenas a subfunção de Checagem, não estamos analisando o estatuto de MD de uma expressão linguística. A subfunção de Checagem integra a variável “orientação da interação", que é apenas uma das variáveis a serem analisadas para se identificar se uma expressão linguística está funcionando como um MD.

Em princípio, mesmo constatando-se que uma expressão tenha a função de Checagem, seu estatuto de MD ainda dependeria dos traços dessa expressão no que se refere às outras variáveis. No entanto, no caso de expressões que têm a subfunção de Checagem, isso parece não se verificar. Conforme temos observado, dada a natureza da subfunção de Checagem, (quase) sempre que uma expressão apresentar essa subfunção, ela será, inevitavelmente, um MD.

Isso pode ser percebido analisando-se os traços das expressões com subfunção de Checagem no que se refere às demais variáveis definidoras dos MDs. Quanto à variável "articulação de segmentos do discurso", como a Checagem constitui um ato discursivo que relaciona falante e ouvinte, como se trata de um ato de natureza retórica e como tem caráter essencialmente retrospectivo, uma expressão com essa subfunção, a nosso ver, não seria capaz de acumular a função de articular dois segmentos do discurso (isto é, não seria capaz de acumular a função de sequenciador, nem tópico, nem frasal). Pelo menos, nenhum autor da Gramática Textual-interativa, até o momento, parece ter identificado alguma 
função de articulação de segmentos do discurso exercida por expressões com a subfunção de Checagem. Ao que tudo indica, expressões com essa função apresentarão sempre a combinação de traços "não-sequenciador e basicamente orientador" (ver traços definidores de MDs em (3) acima).

As expressões de Checagem, em termos sintáticos, constituem em si um enunciado próprio, independente, não sendo, em nenhum caso, um constituinte sintático de uma sentença, e, assim, manifestam sempre o traço "sintaticamente independente". No mesmo sentido, tais expressões não integram o conteúdo proposicional de qualquer outro enunciado, apresentando, pois, o traço "exterior ao conteúdo”.

Em termos de autonomia comunicativa, como a Checagem constitui justamente uma pergunta sobre um segmento anterior do discurso, o enunciado de Checagem nunca terá autonomia comunicativa, devendo, necessariamente, acompanhar outro enunciado comunicativamente central em relação a ele.

Veja-se que um enunciado como “Droga!" “Bom dia!” ou “O jantar está servido.” pode ser o único enunciado de um falante numa situação de interação ou mesmo o único enunciado de uma situação. Já um enunciado como "né?” ou “entende?” em nenhuma situação (normal) poderá ocorrer isoladamente. Assim, expressões com a subfunção de Checagem sempre apresentam o traço "comunicativamente não-autônomo".

Em termos de demarcação prosódica, como os atos de checagem constituem em si um enunciado formalmente interrogativo próprio, eles sempre apresentam o traço "com pauta demarcativa", seja quando sucedem (parte de) um enunciado declarativo, seja quando sucedem (parte de) outro enunciado interrogativo.

Até aqui, todos os traços apresentados pelas expressões de Checagem são traços definidores de MDs prototípicos (não-sequenciador e basicamente orientador, sintaticamente independente, exterior ao conteúdo, comunicativamente não-autônomo, com pauta demarcativa). Pelo que temos analisado até o momento, as expressões com subfunção de Checagem necessariamente apresentarão esses traços.

Já os traços dessas expressões quanto às três variáveis restantes (padrão de recorrência, transparência semântica e massa fônica) podem desviar do conjunto prototípico em (3) acima. Porém, devido às combinações possíveis entre os traços dessas variáveis, esse desvio nunca (ou muito raramente) será suficiente para comprometer o estatuto de MD de uma expressão com a subfunção de Checagem.

Quanto ao padrão de recorrência, dependendo do item com o papel de Checagem e dependendo da extensão do texto, é perfeitamente possível (muito comum, inclusive) que a expressão de Checagem manifeste os traços "baixa frequência" ou "média frequência" (que representariam desvios do conjunto prototípico de traços definidores). 
Quanto à transparência semântica, entendemos que, como se trata de uma pergunta retórica, uma expressão de Checagem nunca poderia ter o traço "totalmente transparente", porque, nesse caso, incidiria sobre o conteúdo do texto, não configurando, pois, um ato de Checagem. Todos os atos de Checagem que temos encontrado têm o traço "parcialmente transparente" (traço prototípico de MDs). Por sua vez, o traço "opaco" (que representaria um desvio), embora nunca tenha se manifestado nos dados que já analisamos, parece-nos condizente com atos de Checagem e possível de manifestar-se em uma ou outra ocorrência.

Até aqui, então, uma expressão de Checagem poderia apresentar dois desvios em relação ao padrão prototípico, isto é, os traços "baixa (ou média) frequência" e "opaco". Como seriam apenas dois traços desviantes, não haveria comprometimento do estatuto de MD. Para a expressão de Checagem não ser um MD, ela deveria apresentar adicionalmente um terceiro desvio, agora na variável "massa fônica", isto é, a expressão teria que apresentar também o traço desviante "além de três sílabas". No entanto, a ocorrência simultânea desses três traços desviantes ("baixa (ou média) frequência", "opaco", "além de três sílabas tônicas") parece-nos muito improvável (senão impossível).7

Em primeiro lugar, todos os atos de Checagem que encontramos e que são atestados por outros autores têm até três sílabas tônicas (traço prototípico). Além disso, a nosso ver, se uma expressão apresentar mais de três sílabas tônicas, dificilmente será semanticamente opaca, porque sua maior extensão fônica provavelmente fará transparecer (total ou parcialmente) seu significado semântico. Assim, a combinação desviante ["baixa (ou média) frequência", "opaco", "além de três sílabas tônicas"] parece-nos rara, senão inexistente. E é, pois, nesse sentido que consideramos que praticamente todas as expressões com a subfunção de Checagem sempre constituirão MDs necessariamente.

\section{Considerações finais}

Neste trabalho, discutimos algumas questões pontuais a respeito da subfunção de Checagem, aqui assumida como uma das possíveis subfunções da função de orientação básica da interação, a qual constitui um dos traços definidores da classe dos MDs na Gramática Textual-interativa. Especificamente, discutimos o conceito de Checagem, a questão da ocorrência de expressões de Checagem após enunciados interrogativos, o caráter da Checagem como imposição, e não propriamente como busca

7. Aqui, estamos considerando que, para uma expressão linguística não poder ser considerada como MD, ela deve manifestar desvio em, pelo menos, três dos traços previstos no padrão prototípico apresentado em (3) acima. 
de aprovação discursiva, a relação entre expressões de Checagem e enunciados interrogativos correspondentes formalmente idênticos e, finalmente, a relação íntima entre a subfunção de Checagem e o estatuto de MD. Ao discutir essas questões, procuramos salientar a natureza retórica da subfunção de Checagem como um de seus aspectos centrais.

Além dessas questões, vários outros pontos sobre a subfunção de Checagem merecem análises mais aprofundadas, como os tipos de unidades escopadas pelos atos de Checagem (enunciados inteiros, partes de enunciados etc.), as funções e os sentidos mais específicos das diferentes expressões de Checagem particulares, dentre outros pontos. Ademais, todos esses tópicos carecem de análises correspondentes em relação às demais subfunções basicamente orientadoras da interação, que incluem, conforme aqui proposto, as subfunções de Retroalimentação, Injunção, Iniciação e Interpelação.

Discussões desse tipo, dentre outros resultados, podem contribuir para especificar e tornar cada vez mais precisa a definição e a descrição de MDs da Gramática Textual-interativa. Considerando a diversidade de elementos que integram essa classe e a variedade de funções que exercem, trata-se de um tipo de discussão plenamente relevante, não apenas no âmbito da Gramática Textual-interativa, mas também no próprio âmbito dos estudos linguísticos em geral.

\section{Artigo recebido: 15/09/2011}

\section{Artigo aceito: 05/11/2011}

\section{Referências}

FISCHER, K. Towards an understanding of the spectrum of approaches to discourse particles: introduction to the volume. In: (Ed.). Approaches to Discourse Particles. Amsterdam: Elsevier, 2006, p.1-20.

FRASER, B. Towards a theory of Discourse Markers. In: FISCHER, K. (Ed.). Approaches to Discourse Particles. Amsterdam: Elsevier, 2006a, p.189-204.

GUERRA, A. R. Funções Textual-Interativas dos Marcadores Discursivos. 2007. 233f. Dissertação (Mestrado em Análise Lingüística) - Instituto de Biociências, Letras e Ciências Exatas, Universidade Estadual Paulista, São José do Rio Preto, 2007.

JUBRAN, C. C. A. S. Uma gramática textual de orientação interacional. In: CASTILHO, A. T.; MORAIS, M. A. T.; LOPES, R. E. V.; CYRINO, S. M. (Orgs.). Descrição, história e aquisição do português brasileiro. Campinas; São Paulo: Pontes; FAPESP, 2007, p.313-327. 
JUBRAN, C. C. A. S.; KOCH, I. G. V. (orgs). Gramática do português culto falado no Brasil - v.I: Construção do texto falado. Campinas: Editora da UNICAMP, 2006.

MARTELOTTA, M. E.; ALCÂNTARA, F. Discursivização na partícula né?. In: MARTELOTTA, M. E.; VOTRE, S. J.; CEZARIO, M. M. Gramaticalização no português do Brasil: uma abordagem funcional. Rio de Janeiro: Tempo Brasileiro/UFRJ, 1996, p. 277-291.

PENHAVEL, E. Marcadores Discursivos e Articulação Tópica. 2010. 168f. Tese (Doutorado em Linguística) - Instituto de Estudos da Linguagem, Universidade Estadual de Campinas, Campinas, 2010.

RISSO, M. S.; SILVA, G. M. O.; URBANO, H. Traços definidores dos Marcadores Discursivos. In: JUBRAN, C. C. A. S.; KOCH, I. G. V. (Orgs). Gramática do português culto falado no Brasil - v.I: Construção do texto falado. Campinas: Editora da UNICAMP, 2006, p.403-425.

SCHIFFRIN, D. Discourse markers. Cambridge: Cambridge University Press, 1987.

URBANO, H. Marcadores discursivos basicamente interacionais. In: JUBRAN, C. C. A. S.; KOCH, I. G. V. (orgs). Gramática do português culto falado no Brasil - v.I: Construção do texto falado. Campinas: Editora da UNICAMP, 2006, p.49-527. 